\title{
An organic redox electrolyte to rival triiodide/iodide in dye-sensitized solar cells
}

\author{
Mingkui Wang ${ }^{1}$, Nathalie Chamberland ${ }^{2}$, Livain Breau², Jacques-E. Moser ${ }^{1}$, Robin Humphry-Baker', \\ Benoît Marsan $^{2 \star}$, Shaik M. Zakeeruddin ${ }^{1 \star}$ and Michael Grätzel ${ }^{1 \star}$
}

Dye-sensitized solar cells (DSCs) have achieved impressive conversion efficiencies for solar energy of over $11 \%$ with an electrolyte that contains triiodide/iodide as a redox couple. Although triiodide/iodide redox couples work efficiently in DSCs, they suffer from two major disadvantages: electrolytes that contain triiodide/iodide corrode electrical contacts made of silver (which reduces the options for the scale up of DSCs to module size) and triiodide partially absorbs visible light. Here, we present a new disulfide/thiolate redox couple that has negligible absorption in the visible spectral range, a very attractive feature for flexible DSCs that use transparent conductors as current collectors. Using this novel, iodide-free redox electrolyte in conjunction with a sensitized heterojunction, we achieved an unprecedented efficiency of $6.4 \%$ under standard illumination test conditions. This novel redox couple offers a viable pathway to develop efficient DSCs with attractive properties for scale up and practical applications.

S ince the beginning of the 1990s much attention has been paid to alternative energy sources, in particular to photovoltaic solar energy ${ }^{1,2}$. DSCs (or Grätzel cells) currently attract considerable interest because of their high light-to-electricity conversion efficiencies, relatively easy fabrication procedures and low production cost ${ }^{3}$. The most common electrolyte in high-performance DSCs uses the triiodide/iodide $\left(\mathrm{I}_{3}^{-} / \mathrm{I}^{-}\right)$redox couple $e^{4-6}$. Even though this redox couple works efficiently, it has disadvantages, such as the corrosion of silver-based current collectors and the partial absorption of visible light around $430 \mathrm{~nm}$ by the triiodide species ${ }^{7}$. Therefore, it is important to study alternative redox couples ${ }^{8-11}$, including $p$-type semiconductors $^{12}$ and solid-state, hole-transporting materials ${ }^{13}$. Electrolytes composed of a high molecular weight poly(ethylene oxide)-based copolymer in complex with an alkali metal polysulfide $\left(\mathrm{M}_{2} \mathrm{~S}_{n}\right.$; redox couple $\mathrm{S}_{n}{ }^{2-} / \mathrm{S}_{n+1}{ }^{2-}$ ) or a caesium thiolate salt (redox couple disulfide/thiolate) are used successfully in all solid-state, electrochemical photovoltaic cells (n-CdSe|polymer redox electrolyte|ITO, where ITO represents the indium-tin-oxide conductive layer on the glass electrode $)^{14,15}$. These studies encouraged us to introduce disulfide/thiolate $\left(\mathrm{T}_{2} / \mathrm{T}^{-}\right)$molecules (instead of $\mathrm{I}_{3}^{-} / \mathrm{I}^{-}$ones) as redox mediators in DSC electrolytes.

\section{Results and discussion}

Characterization of the DSC redox couple. The redox couple $\mathrm{T}_{2} / \mathrm{T}^{-}$, where $\mathrm{T}^{-}$represents the 5-mercapto-1-methyltetrazole ion and $\mathrm{T}_{2}$ stands for its dimer (Fig. 1), was characterized electrochemically (Supplementary Fig. S1) and studied as an electrolyte for DSCs. The redox potential for $\mathrm{T}_{2} / \mathrm{T}^{-}$was found to be $0.485 \mathrm{~V}$ against a normal hydrogen electrode (NHE, Supplementary Fig. S1), which is close to that of the $\mathrm{I}_{3}{ }^{-} / \mathrm{I}^{-}$redox couple (reported values range from $0.4 \mathrm{~V}$ to $0.53 \mathrm{~V}$ against NHE in organic solvents ${ }^{16,17}$ ) used in a DSC. Delocalization of the negative charge formally on the sulfur atom to the nitrogen atoms of the tetrazole ring is recognized as the important factor that facilitates the solubility and dissociation of the tetramethylammonium salt in the aprotic solvent. The $\mathrm{N}\left(\mathrm{CH}_{3}\right)_{4}^{+}$ counterion, similarly, helps to dissolve the thiolate salt.
$\mathrm{T}_{2}$ and its tetramethylammonium salt $\left(\mathrm{T}^{-}\right)$are colourless, whereas their mixture is pale yellow and absorbs light to a negligible extent under thin-layer conditions (Supplementary Fig. S2). This feature is very attractive for flexible DSCs fabricated on metal foils, where the devices are illuminated through the counter-electrode side.

After optical excitation of the dye and subsequent ultrafast electron injection into the $\mathrm{TiO}_{2}$ conduction band (reaction (1), Fig. 1), the oxidized dye cation is reduced by electron donation from the $\mathrm{T}^{-}$species (reaction (3), Fig. 1). When two $\mathrm{T}^{\bullet}$ radicals are formed, they combine to form $\mathrm{T}_{2}$ (reaction (4), Fig. 1). At the counter electrode, the electrons from the $\mathrm{TiO}_{2}$ conduction band that arrive through the external circuit reduce $T_{2}$ to regenerate the $T^{-}$species (reaction (6), Fig. 1).

Photovoltaic performance. Some preliminary photovoltaic experiments were conducted to evaluate the performance of the new redox couple as the electroactive component of an electrolyte in a DSC. The concentration ratio between the reduced and

$$
\begin{aligned}
& \mathrm{Z}-907 \mathrm{Na}\left|\mathrm{TiO}_{2}+h v \rightarrow \mathrm{Z}-907^{\star}\right| \mathrm{TiO}_{2} \rightarrow \mathrm{Z}-907^{+} \mid \mathrm{TiO}_{2}+e_{\mathrm{cb}}{ }^{-} \\
& \mathrm{Z}-907^{+}\left|\mathrm{TiO}_{2}+e_{\mathrm{cb}}^{-} \rightarrow \mathrm{Z}-907\right| \mathrm{TiO}_{2} \\
& \mathrm{Z}-907^{+}\left|\mathrm{TiO}_{2}+\mathrm{T}^{-} \rightarrow \mathrm{Z}-907\right| \mathrm{TiO}_{2}+\mathrm{T}^{\cdot} \\
& 2 \mathrm{~T}^{\bullet} \rightarrow \mathrm{T}_{2} \\
& \mathrm{Z}-907^{+}\left|\mathrm{TiO}_{2}+2\right|^{-} \rightarrow \mathrm{Z}-907 \mid \mathrm{TiO}_{2}+\mathrm{I}_{2}^{-} \\
& \mathrm{T}_{2}+2 e^{-} \rightarrow 2 \mathrm{~T}^{-}
\end{aligned}
$$

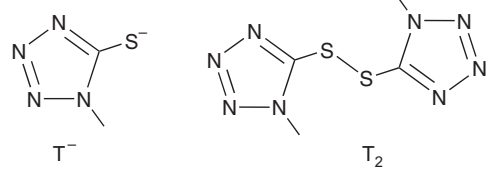

Figure 1 | Light-induced electron transfer reactions in DSCs. The novel $\mathrm{T}_{2} / \mathrm{T}^{-}$redox couple and its intervention in DSCs. $\mathrm{Z}-907^{+}$, the oxidized dye; $e_{\mathrm{cb}}{ }^{-}$, electrons in the conduction band of the semiconductor.

${ }^{1}$ Laboratory for Photonics and Interfaces, Swiss Federal Institute of Technology, CH 1015, Lausanne, Switzerland, ${ }^{2}$ Département de Chimie, Université du Québec à Montréal, C.P. 8888, Succursale Centre-Ville, Montréal, Quebec, H3C 3P8, Canada. *e-mail: shaik.zakeer@epfl.ch; michael.graetzel@epfl.ch; 
Table 1 | Photovoltaic characteristics of devices A-F.

\begin{tabular}{|c|c|c|c|c|c|c|c|c|c|c|c|c|}
\hline \multirow[b]{2}{*}{ Electrolyte } & \multicolumn{2}{|c|}{ A } & \multicolumn{2}{|c|}{ B } & \multicolumn{2}{|c|}{ C } & \multicolumn{2}{|c|}{ D } & \multicolumn{2}{|c|}{ E } & \multicolumn{2}{|c|}{$\mathbf{F}$} \\
\hline & \multicolumn{2}{|c|}{$\mathrm{I}$} & \multicolumn{2}{|c|}{ II } & \multicolumn{2}{|c|}{ III } & \multicolumn{2}{|c|}{ IV } & \multicolumn{2}{|c|}{ IV } & \multicolumn{2}{|c|}{ V } \\
\hline Composition & \multicolumn{2}{|c|}{$\begin{array}{l}\mathrm{T}_{2} / \mathrm{T}^{-} \\
(0.1 \mathrm{M} / 0.4 \mathrm{M})\end{array}$} & \multicolumn{2}{|c|}{$\begin{array}{l}\mathrm{T}_{2} / \mathrm{T}^{-} \\
(0.4 \mathrm{M} / 0.4 \mathrm{M})\end{array}$} & \multicolumn{2}{|c|}{$\begin{array}{l}\mathrm{T}_{2} / \mathrm{T}^{-} \\
(1.0 \mathrm{M} / 0.4 \mathrm{M})\end{array}$} & \multicolumn{2}{|c|}{$\begin{array}{l}\mathrm{T}_{2} / \mathrm{T}^{-}, \mathrm{TBP}, \\
\mathrm{LiClO}_{4} \\
(0.4 \mathrm{M} / 0.4 \mathrm{M} \\
0.5 \mathrm{M}, 0.05 \mathrm{M})\end{array}$} & \multicolumn{2}{|c|}{$\begin{array}{l}\mathrm{T}_{2} / \mathrm{T}^{-}, \mathrm{TBP}, \\
\mathrm{LiClO}_{4} \\
(0.4 \mathrm{M} / 0.4 \mathrm{M}, \\
0.5 \mathrm{M}, 0.05 \mathrm{M})\end{array}$} & \multicolumn{2}{|c|}{$\begin{array}{l}\mathrm{DMII} / \mathrm{I}_{2} \\
(0.8 \mathrm{M} / 0.4 \mathrm{M})\end{array}$} \\
\hline $\mathrm{TiO}_{2}$ films & \multicolumn{2}{|c|}{$8+5 \mu \mathrm{m}$} & \multicolumn{2}{|c|}{$8+5 \mu m$} & \multicolumn{2}{|c|}{$8+5 \mu m$} & \multicolumn{2}{|c|}{$8+5 \mu \mathrm{m}$} & \multicolumn{2}{|c|}{$11+5 \mu \mathrm{m}$} & \multicolumn{2}{|c|}{$8+5 \mu \mathrm{m}$} \\
\hline Incident light (sun) & 1.0 & 0.1 & 1.0 & 0.1 & 1.0 & 0.1 & 1.0 & 0.1 & 1.0 & 0.1 & 1.0 & 0.1 \\
\hline$V_{O C}(m V)$ & 655 & 607 & 656 & 605 & 614 & 562 & 696 & 645 & 681 & 625 & 676 & 603 \\
\hline$J_{\mathrm{sc}}\left(\mathrm{mA} \mathrm{cm} \mathrm{cm}^{-2}\right)$ & 10.205 & 1.289 & 12.166 & 1.394 & 10.66 & 1.245 & 14.231 & 1.538 & 16.18 & 1.713 & 12.81 & 1.315 \\
\hline FF & 0.62 & 0.73 & 0.63 & 0.75 & 0.56 & 0.71 & 0.58 & 0.73 & 0.58 & 0.76 & 0.75 & 0.76 \\
\hline$\eta(\%)$ & 4.13 & 5.74 & 4.99 & 6.31 & 3.66 & 4.97 & 5.79 & 7.26 & 6.44 & 8.14 & 6.48 & 6.04 \\
\hline
\end{tabular}

Detailed photovoltaic parameters of Z907Na-sensitized devices with varying film thickness and electrolyte composition under different light intensities (1 sun and 0.1 sun).

oxidized species (details of the synthetic methods are given in the Supplementary Information) was first optimized by using different concentrations of the oxidized species $(0.1 \mathrm{M}, 0.4 \mathrm{M}$ and $1.0 \mathrm{M})$, with the reduced species concentration kept constant at $0.4 \mathrm{M}$.

As listed in Table 1, five electrolytes were formulated and tested in the DSC (devices A to F). All the electrolytes were made with acetonitrile and ethylene carbonate (6:4 volume ratio) as solvent. Electrolyte IV was examined with the additives 4-tert-butylpyridine (TBP) and $\mathrm{LiClO}_{4}$ (devices $\mathrm{D}$ and $\mathrm{E}$ ). Electrolyte $\mathrm{V}$, which contained the $\mathrm{I}_{3}^{-} / \mathrm{I}^{-}$redox couple, was used for comparison (device $\mathrm{F}$ ).

Double-layer, nanocrystalline titania films (of thickness $8+5 \mu \mathrm{m}$ for devices $\mathrm{A}-\mathrm{D}$ and $\mathrm{F}$, and $11+5 \mu \mathrm{m}$ for device $\mathrm{E}$ (Table 1)) were used to support the amphiphilic ruthenium sensitizer $\mathrm{Na}\left(\mathrm{Ru}(4\right.$-carboxylic acid-4'-carboxylate $)\left(4,4^{\prime}\right.$-dinonyl-2,2' bipyridine)(NCS $)_{2}$ ), coded as Z-907Na. The same notation for the double-layer thickness is used throughout: $8+5 \mu \mathrm{m}$, for example, means an eight-micrometre-thick transparent nanocrystalline $\mathrm{TiO}_{2}$ layer (20-30 nm particle size) onto which a second, five-micrometrethick, layer of larger light-scattering $\mathrm{TiO}_{2}$ particles $(200-400 \mathrm{~nm}$ particle size) is deposited. Detailed fabrication procedures for the cells are described in the Supplementary Information.

The photocurrent density-voltage $(J-V)$ characteristics of devices B, D, E and F are depicted in Fig. 2. The detailed photovoltaic parameters, that is the open-circuit voltage $\left(V_{\mathrm{oc}}\right)$, fill factor $(F F)$, short-circuit current density $\left(J_{\mathrm{sc}}\right)$ and photovoltaic conversion efficiency $(\eta)$ for devices A-F are given in Table 1. Comparing devices $\mathrm{A}$ and $\mathrm{B}$ with device $\mathrm{C}$, the $V_{\mathrm{oc}}$ decreased with an increase in the concentration of the oxidized species in the electrolytes, because of the increase of the dark current. Interestingly, the $J_{\mathrm{sc}}, V_{\mathrm{oc}}$ and $F F$ values of device B with electrolyte II are $12.17 \mathrm{~mA} \mathrm{~cm}^{-2}$, $656 \mathrm{mV}$ and 0.63 , respectively, which yield an overall powerconversion efficiency of $5.0 \%$, higher than that of $4.0 \%$ reported previously for the corresponding device with an iodide-free, Co(III/II) complexes-based volatile electrolyte ${ }^{18,19}$. Changing the redox couple from $\mathrm{T}_{2} / \mathrm{T}^{-}$to $\mathrm{I}_{3}^{-} / \mathrm{I}^{-}$(with the same oxidized species concentration) in device $\mathrm{F}$ (Fig. 2, grey curve) resulted in a $6.5 \%$ overall powerconversion efficiency, attributed principally to the higher fill factor. Under a lower light intensity (10\% sun), device B had a higher power-conversion efficiency than that of device $\mathrm{F}$ using the $\mathrm{I}_{3}{ }^{-} / \mathrm{I}^{-}$ redox couple (6.3\% versus $6.0 \%)$, which substantiates the promising potential for this new redox couple.

The conversion efficiency from incident photon to current (IPCE) is given by $\operatorname{IPCE}(\lambda)=\left(\mathrm{I}(\lambda) / P_{\text {in }}(\lambda)\right)(h c / e \lambda)$, where $\lambda$ is the wavelength, $I(\lambda)$ is the photocurrent measured under monochromatic illumination at $\lambda$ with an irradiation intensity of $P_{\text {in }}(\lambda)$, $h$ is the Planck constant, $c$ is the speed of light and $e$ is the elementary charge. The IPCEs of devices B, D, E and F are shown in Fig. 3 (left ordinate). Compared to device $\mathrm{F}$ (which contains $\mathrm{I}_{3}{ }^{-} / \mathrm{I}^{-}$), device $\mathrm{B}$ (with $\mathrm{T}_{2} / \mathrm{T}^{-}$as a redox couple without additives) has a broader IPCE in the spectral range $360-460 \mathrm{~nm}$. Thus, from wavelengths $360 \mathrm{~nm}$ to $460 \mathrm{~nm}$ an increase in the integrated current $\left(2.03 \mathrm{~mA} \mathrm{~cm}^{-2}\right.$ versus $1.49 \mathrm{~mA} \mathrm{~cm}^{-2}$ between devices $B$ and F (Fig. 3, right ordinate)) of $36 \%$ was obtained, which clearly shows the advantage of this redox couple. This could be the result of a much lower light absorption of the new redox couple compared to that of $\mathrm{I}_{3}^{-} / \mathrm{I}^{-}$(Supplementary Fig. S2). The dark current-voltage characteristics of these two devices (B and F) are shown in Fig. 2 and Supplementary Fig. S3. The onset of the dark current of device F occurred at a low forward bias, whereas the use of the new redox couple (electrolyte II) suppressed the dark current, shifting its onset by about $100 \mathrm{mV}$.

The presence of additives (TBP and $\mathrm{Li}^{+}$ions) in electrolyte IV enhanced the photovoltaic performance of device D to $5.8 \%$ (Fig. 2, green curve). By increasing the thickness of the $20 \mathrm{~nm}$ titania transparent film from 8 to $11 \mu \mathrm{m}$ in a double-layer structure (device E), the efficiency was further improved to $6.44 \%$ (Fig. 2, blue curve). At a lower light intensity $\left(10 \mathrm{~mW} \mathrm{~cm}^{-2}\right)$, the efficiency of the device was as high as $8.1 \%$ (Table 1). The IPCE of device E is very high, greater than $60 \%$ in the spectral range from 400 to $640 \mathrm{~nm}$ with a maximum of $85 \%$ at $540 \mathrm{~nm}$. To the best of our

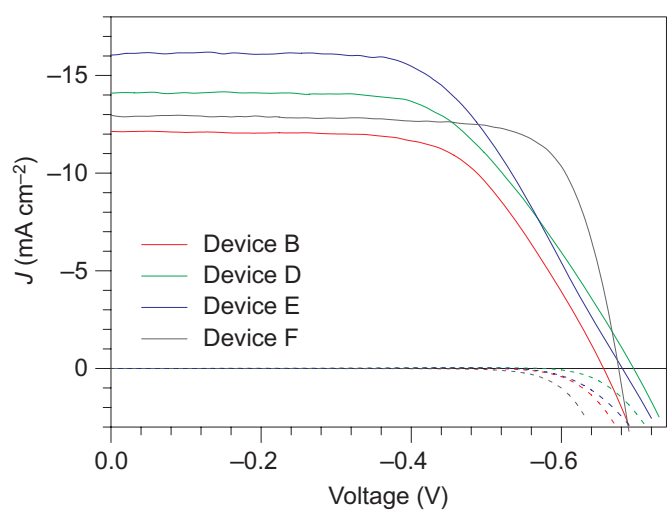

Figure 2 | Photocurrent density-voltage $(J-V)$ and dark current characteristics of DSCs using $\mathrm{T}_{2} / \mathrm{T}^{-}$or $\mathrm{I}_{3}^{-} / \mathrm{I}^{-}$as the redox couple. The electrolyte composition of electrolyte II in device $\mathrm{B}(8+5 \mu \mathrm{m}$ double-layer $\mathrm{TiO}_{2}$ film) was $0.4 \mathrm{M} \mathrm{T}_{2}$ and $0.4 \mathrm{M} \mathrm{T}^{-}$, that of electrolyte IV in devices $\mathrm{D}$ $\left(8+5 \mu \mathrm{m}\right.$ double-layer $\mathrm{TiO}_{2}$ film $)$ and $\mathrm{E}\left(11+5 \mu \mathrm{m}\right.$ double-layer $\mathrm{TiO}_{2}$ film $)$ was $0.4 \mathrm{M} \mathrm{T}_{2}$ and $0.4 \mathrm{M} \mathrm{T}^{-}$with $0.5 \mathrm{M}$ tert-butylpyridine and $0.05 \mathrm{M}$ $\mathrm{LiClO}_{4}$, and that of electrolyte $\mathrm{V}$ in device $\mathrm{F}\left(8+5 \mu \mathrm{m}\right.$ double-layer $\mathrm{TiO}_{2}$ film) was $0.8 \mathrm{M} \mathrm{1,3-dimethylimidazolium} \mathrm{iodide} \mathrm{(DMII)} \mathrm{and} 0.4 \mathrm{M} \mathrm{I}_{2}$ (see Table 1). Acetonitrile-ethylene carbonate (6:4 volume ratio) was used as solvent for all the electrolytes. Dotted lines correspond to the dark-current measurement. Cells were tested using a metal mask with an aperture area of $0.158 \mathrm{~cm}^{2}$ and measured under air mass 1.5 global (AM $1.5 \mathrm{G}$ ) $\left(100 \mathrm{~mW} \mathrm{~cm}^{-2}\right)$. 


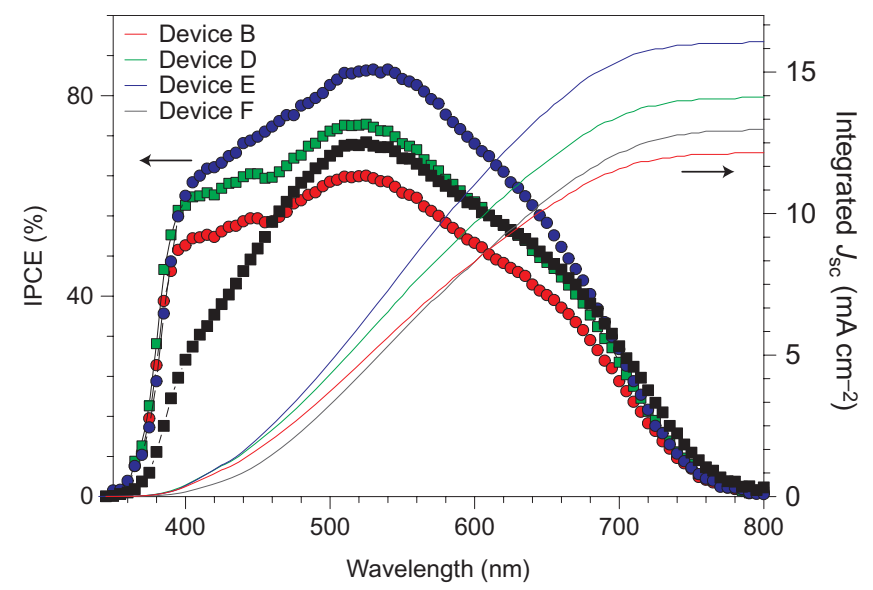

Figure 3 | Spectral response of the photocurrent of DSCs using $T_{2} / T^{-}$or $\mathrm{I}_{3}^{-} / \mathrm{I}^{-}$as the redox mediator. The left ordinate shows the IPCE as a function of the wavelength of monochromatic light that impinges on the cell (filled symbols). The right ordinate shows the overlap integral of the IPCE with AM $1.5 \mathrm{G}$ solar emission up to the wavelength shown on the abscissa. Hence, the right ordinate projects the photocurrent $\left(J_{\mathrm{sc}}\right)$ expected to be generated under the standard reporting solar condition. The devices are described in Fig. 2; devices B, D and E refer to electrolytes II and IV and the control device $\mathrm{F}$ to electrolyte $\mathrm{V}$ (see Table 1).

knowledge, this is the highest power-conversion efficiency under full sunlight conditions reported for a DSC that does not use $\mathrm{I}_{3}^{-} / \mathrm{I}^{-}$as a redox mediator ${ }^{8,20}$. Previously, with a similar thick, double-layer $\mathrm{TiO}_{2}$ film, we obtained an efficiency of over $9.5 \%$ using an optimized volatile $\mathrm{I}_{3}^{-} / \mathrm{I}^{-}$electrolyte ${ }^{21,22}$.

As indicated in Fig. 2 and Table 1, the DSC devices that use the $T_{2} / T^{-}$redox couple have lower fill factors, which limit the overall efficiency $\left(\eta=V_{\mathrm{oc}} \times J_{\mathrm{sc}} \times F F\right)$. The current dynamics (Supplementary Fig. S4) and impedance (Supplementary Figs S5-S7) studies show that the low fill factor is not limited by the diffusion of $T_{2}$ in the electrolytes. Rather, it is caused by slow kinetics of the electrochemical reaction (reaction (6), Fig. 1) at the Pt/FTO electrode surface (FTO is the fluorine-doped $\mathrm{SnO}_{2}$ conducting glass) referenced by much lower exchange-current densities $\left(J_{0}\right)$ of electrolytes based on $\mathrm{T}_{2} / \mathrm{T}^{-}$than those of electrolytes based on $\mathrm{I}_{3}^{-} / \mathrm{I}^{-}$. Future studies will seek a suitable catalyst on the counter electrode that improves the fill factor of devices made with this novel redox couple.

Nanosecond time-resolved laser study. Nanosecond time-resolved laser experiments were carried out to elucidate the kinetics of the interception of dye cation by $\mathrm{T}^{-}$compared with $\mathrm{I}^{-}$(that is, the dye regeneration reaction with the reduced form of redox couples by reaction (3) or (5) (Fig. 1)). The transient optical signal observed at $\lambda=650 \mathrm{~nm}$ records the concentration of the oxidized state of the Z-907Na ruthenium sensitizer after ultrafast, photoinduced electron injection from the dye into the conduction band of $\mathrm{TiO}_{2}$ (reaction (1), Fig. 1$)^{21}$. In the absence of redox electrolyte, the decrease in the absorbance signal reflects the dynamics of the recombination of conduction-band electrons with the oxidized dye $\mathrm{Z}-907^{+}$(reaction (2), Fig. 1). The pulsed laser intensity was kept at a low level $\left(\leq 40 \mu \mathrm{J} \mathrm{cm}^{-2}\right.$ per pulse) to ensure that, on average, less than one $e_{\mathrm{cb}}{ }^{-} / \mathrm{Z}-907^{+}$charge-separated pair was produced per nanocrystalline particle on pulsed irradiation (where $e_{\mathrm{cb}}{ }^{-}$is an electron in the conduction band of the semiconductor). The intensity of the monochromatic probe light that reaches the sample was also attenuated to less than $1 \mathrm{~mW} \mathrm{~cm}^{-2}$ to minimize the steady-state carrier concentration. In such conditions, a half-reaction time $\left(t_{1 / 2}\right)$ of $180 \mu \mathrm{s}$ was measured for the $e_{\mathrm{cb}}{ }^{-} / \mathrm{Z}-907^{+}$recombination (Fig. 4, black curve).
In the presence of electrolyte II, which contained $\mathrm{T}_{2} / \mathrm{T}^{-}$in a $1: 1$ molar ratio, the decay of the oxidized dye accelerated markedly. A $t_{1 / 2}$ of $20 \mu$ s was measured (Fig. 4, green curve), which indicates that the sensitizer was regenerated quickly and the back reaction was intercepted efficiently by the mediator (reaction (3), Fig. 1). In this case, we observed that the absorbance change reached a pseudo-plateau at approximately $20 \%$ of the initial signal magnitude, $300 \mu$ s after the excitation pulse. This residual absorbance, which decayed down to the baseline within a few hundred microseconds, is attributed to the $\mathrm{T}^{\bullet}$ radical, the one-electron oxidation product of the mediator, for which the absorption spectrum should be significant at the probe wavelength of $650 \mathrm{~nm}$.

For comparison, measurements were carried out in similar conditions with electrolyte V. A $t_{1 / 2}$ of $10 \mu$ s was measured (Fig. 4, red curve) for dye regeneration (reaction (5), Fig. 1), shorter by a factor of two than that obtained with electrolyte II. The presence of $\mathrm{Li}^{+}$cations $(0.05 \mathrm{M})$ in electrolyte IV (Fig. 4, blue curve) improved the interception rate, which became almost identical to that measured for iodide. The rather slow kinetics observed for the one-electron oxidation of $\mathrm{T}^{-}$to yield the $\mathrm{T}^{\bullet}$ radical (reaction (3), Fig. 1) suggests that the driving force of the reaction is comparable to that observed for iodide (reaction (5), Fig. 1). The effect of $\mathrm{Li}^{+}$cations can probably be attributed to the lower negative charge carried by the sensitized oxide surface and subsequently to a facilitated approach of $\mathrm{T}^{-}$anions in the vicinity of the ruthenium dye.

Results of photovoltage transient decay and charge extraction measurements. We demonstrated previously ${ }^{22}$ that the presence of different hole-transporting materials influences recombination between the oxidized redox couple and the photoinjected electrons in $\mathrm{TiO}_{2}$, and thus on the photovoltaic performance of the device (fabricated using volatile, low volatility or ionic liquid electrolytes). The charge-recombination kinetics and electron-diffusion dynamics in the DSC devices were derived using the methodology proposed

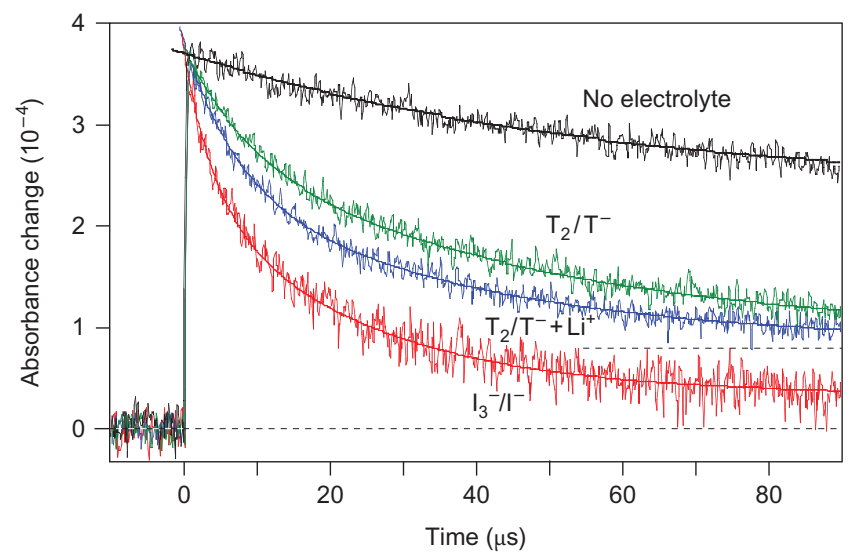

Figure 4 | Charge-transfer dynamics at the dye-sensitized heterojunction measured by nanosecond laser flash photolysis. The decay of the transient absorbance that arises from the oxidized state of the Z-907Na sensitizer adsorbed on nanocrystalline $\mathrm{TiO}_{2}$ films in an acetonitrile-ethylene carbonate solvent mixture. The vertical rise of the absorbance at time zero corresponds to the generation of oxidized sensitizer caused by ultrafast electron injection in the $\mathrm{TiO}_{2}$ conduction band from the excited state of Z-907Na during the laser pulse ( $\lambda=532 \mathrm{~nm}, 7 \mathrm{~ns}$ pulse duration). The traces display the time course of the decay of the oxidized dye caused by recapture of the electrons or regeneration of the dye by the redox mediator in the electrolyte. Black curve $=$ no electrolyte added $\left(t_{1 / 2}=180 \mu \mathrm{s}\right)$; red curve = electrolyte $\mathrm{V}$, $\mathrm{I}_{3}^{-} / \mathrm{I}^{-}\left(t_{1 / 2}=10 \mu \mathrm{s}\right)$; green curve $=$ electrolyte $\mathrm{II}, \mathrm{T}_{2} / \mathrm{T}^{-}$redox mediator $\left(t_{1 / 2}=20 \mu \mathrm{s}\right) ;$ blue curve = electrolyte $\mathrm{IV}_{1} \mathrm{~T}_{2} / \mathrm{T}^{-}$with $\mathrm{Li}^{+}$ions and TBP added $\left(t_{1 / 2}=12 \mu \mathrm{s}\right)$. 

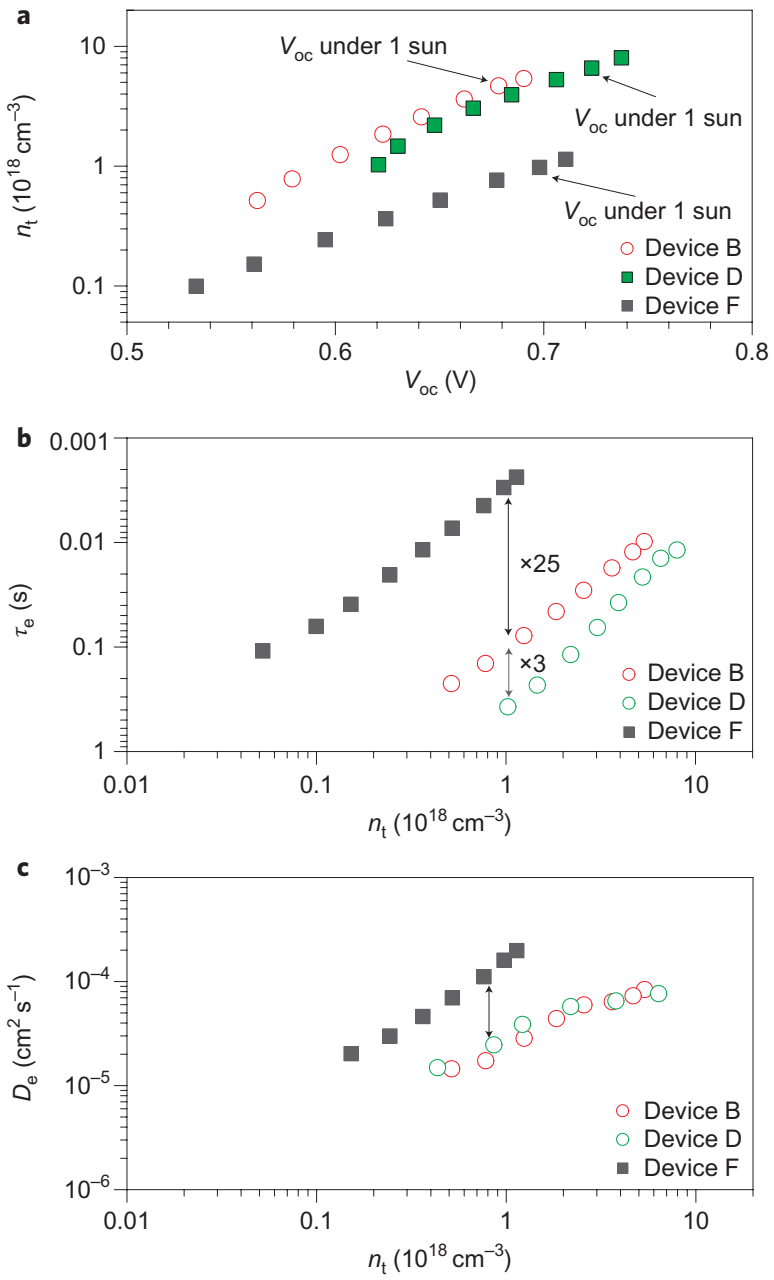

Figure 5 | Dynamics of charge transport and recombination derived from photovoltage and photocurrent transient decay and charge-extraction measurements. a, Extracted charge density in DSCs based on thin $\mathrm{TiO}_{2}$ nanocrystalline film using electrolyte II, electrolyte IV and electrolyte $\mathrm{V}$, as a function of $V_{\text {oc }}$ b,c, Charge-recombination lifetime $\left(\tau_{\mathrm{e}}\right)(\mathbf{b})$ and electrondiffusion coefficients $\left(D_{\mathrm{e}}\right)(\mathbf{c})$ of the three devices from transient photovoltage measurements at an open circuit. The horizontal axes in (b) and (c) show the extracted charge density under the same intensity as used for the transient photovoltage measurements.

by O'Regan et al. ${ }^{23}$ at open-circuit conditions using a short light pulse superimposed on the direct current illumination.

Figure 5a shows the extracted charge density $\left(n_{\mathrm{t}}\right)$ in devices that use different electrolytes at $V_{\text {oc }}$ under varying light intensities. The charge versus $V_{\text {oc }}$ curve for $\mathrm{T}_{2} / \mathrm{T}^{-}$is shifted to voltages approximately $100 \mathrm{mV}$ lower than that for the $\mathrm{I}_{3}^{-} / \mathrm{I}^{-}$electrolyte (device $\mathrm{F}$ ). Figure $5 \mathrm{~b}$ compares the charge-recombination lifetime $\left(\tau_{\mathrm{e}}\right)$ of DSCs with different electrolytes as a function of $n_{\mathrm{t}}$. Notably, device $\mathrm{B}$, which uses the $\mathrm{T}_{2} / \mathrm{T}^{-}$redox couple, has a charge-recombination lifetime about 25 times longer than that of device $\mathrm{F}$ under identical charge-density conditions. Compared to device B, the additives (TBP and $\mathrm{Li}^{+}$ions) in device $\mathrm{D}$ further increased (by a factor of three) the recombination lifetime. Consequently, we would expect the DSC of $\mathrm{T}_{2} / \mathrm{T}^{-}$to have a higher $V_{\mathrm{oc}}$ than that of $\mathrm{I}_{3}{ }^{-} / \mathrm{I}^{-}$, assuming the same quantum yield, incident photon flux and concentrations of oxidized species ${ }^{24}$. However, we observed that the $V_{\text {oc }}$ of device $\mathrm{F}$ was higher than that of device $\mathrm{B}$, but this result is not surprising as $V_{\text {oc }}$ can also be influenced by other parameters, such as the adsorbed proton concentration on the surface of $\mathrm{TiO}_{2}$. As we did not use a buffer, such as TBP, in the electrolytes of devices $\mathrm{B}$ and $\mathrm{F}$, the conduction-band edge of $\mathrm{TiO}_{2}$ can differ, depending on the number of protons adsorbed during the sensitization process. As illustrated in Fig. 5a, in the case of device $\mathrm{B}$ the downward (against vacuum) shift of the $\mathrm{TiO}_{2}$ conduction band was responsible for the observed lower $V_{\text {oc. }}$. The chemical capacitance $\left(C_{\mu}\right.$, Supplementary Fig. S9) and the electronic transport resistance in the nanocrystalline titania film $\left(R_{\mathrm{t}}\right.$, Supplementary Fig. S10) also trace the conduction-band movements. In device $\mathrm{B}$, as compared to device $\mathrm{F}$, at a given $R_{\mathrm{t}}$ there is a $50 \mathrm{mV}$ shift, which corresponds to about a $100 \mathrm{mV}$ downward shift in the energy level of the conduction-band edge of $\mathrm{TiO}_{2}$. The electron-diffusion coefficient $\left(D_{\mathrm{e}}\right)$ values of the Z-907Na dyeloaded photoanodes in electrolyte II are about ten times lower than those for electrolyte $\mathrm{V}$ under identical charge-density conditions (ranging from $10^{-5} \mathrm{~cm}^{2} \mathrm{~s}^{-1}$ to $10^{-4} \mathrm{~cm}^{2} \mathrm{~s}^{-1}$ (Fig. $5 \mathrm{c}$ )). $D_{\mathrm{e}}$ follows a power law with light intensity as a result of trap filling by electrons generated from the bias light.

\section{Conclusions}

In summary, we demonstrate here that a new electrolyte based on a $\mathrm{T}_{2} / \mathrm{T}^{-}$redox couple can be used as a mediator for high-efficiency DSCs. This is the first alternative redox couple identified that can rival the performance of the triiodide/iodide couple.

An efficiency of $6.4 \%$ achieved under full sunlight sets a new benchmark for iodide-free DSCs, and the lower light absorption of the redox couple in the range of $400-450 \mathrm{~nm}$ is advantageous over the $\mathrm{I}_{3}^{-} / \mathrm{I}^{-}$redox couple. This is expected to have important practical consequences as the need for transparent, organic solvent-based, non-corrosive electrolytes to achieve high powerconversion efficiencies for flexible cells increases. Work is in progress to optimize the structures of the oxidized and reduced forms of this novel redox couple, as well as the electrolyte composition, and so improve further the performance of this promising system.

\section{Methods}

In this work, the standard amphiphilic polypyridyl ruthenium complex, cis$\operatorname{RuLL}^{\prime}(\mathrm{SCN})_{2}\left(\mathrm{~L}=4\right.$-dicarboxylicacid- $4^{\prime}$-carboxylate- $2,2^{\prime}$-bipyridine, $\mathrm{L}^{\prime}=4,4^{\prime}$ dinonyl-2,2' -bipyridine) (Z-907Na) was used as sensitizer for the DSC (the synthesis is described elsewhere $\left.{ }^{21}\right)$. For solar-cell fabrication and characterization we used our previous method ${ }^{25}$. Nanosecond laser transient absorbance measurements were used to characterize the reaction kinetics, as described elsewhere ${ }^{21}$. The electronrecombination lifetime and electron diffusion coefficient were determined by transient photovoltage decay and charge-extraction measurements. Electrochemical impedance spectroscopy measurements were carried out with an Autolab Frequency Analyzer setup, which consisted of an Autolab PGSTAT 30 (Eco Chemie, Utrecht), which produces a small amplitude harmonic voltage, and a Frequency Response Analyzer module. Further information can be found in the Supplementary Information.

Received 3 November 2009; accepted 19 February 2010; published online 4 April 2010

\section{References}

1. Shah, A. et al. Photovoltaic technology: the case for thin-film solar cells. Science 285, 692-698 (1999).

2. Brabec, C. et al. Plastic solar cells. Adv. Funct. Mater. 11, 15-28 (2001).

3. O’Regan, B. \& Grätzel, M. A low-cost, high-efficiency solar cell based on dye-sensitized colloidal $\mathrm{TiO}_{2}$ films. Nature 353, 737-740 (1991).

4. Chiba, Y. et al. Dye-sensitized solar cells with conversion efficiency of $11.1 \%$. J. Appl. Phys. 45, L638-L640 (2006).

5. Nazeeruddin, M. et al. Engineering of efficient panchromatic sensitizers for nanocrystalline $\mathrm{TiO}_{2}$-based solar cells. J. Am. Chem. Soc. 123, 1613-1624 (2001).

6. Gao, F. et al. Enhance the optical absorptivity of nanocrystalline $\mathrm{TiO}_{2}$ film with high molar extinction coefficient ruthenium sensitizers for high performance dye-sensitized solar cells. J. Am. Chem. Soc. 130, 10720-10728 (2008).

7. Martinson, A. B. F. et al. New architectures for dye-sensitized solar cells. Chem. Eur. J. 14, 4458-4467 (2008).

8. Zhang, Z. et al. The 2,2,6,6-tetramethyl-1-piperidinyloxy radical: an efficient, iodine- free redox mediator for dye-sensitized solar cells. Adv. Funct. Mater. 18, 341-346 (2008).

9. Snaith, H. J. et al. Dye-sensitized solar cells incorporating a 'liquid' hole-transporting material. Nano. Lett. 6, 2000-2003 (2006). 
10. Cameron, P. J. et al. Electrochemical studies of the $\mathrm{Co}^{(\mathrm{III})} / \mathrm{Co}^{(\mathrm{III})}(\mathrm{dbbip})_{2}$ redox couple as a mediator for dye-sensitized nanocrystalline solar cells. Coord. Chem. Rev. 248, 1447-1453 (2004).

11. Yanagida, S. et al. Iodine/iodide-free dye-sensitized solar cells. Acc. Chem. Res. 42, 1827-1838 (2009).

12. O’Regan, B. et al. Electrodeposited nanocomposite $n-p$ heterojunctions for solid-state dye-sensitized photovoltaics. Adv. Mater. 12, 1263-1267 (2000).

13. Bach, U. et al. Solid-state dye-sensitized mesoporous $\mathrm{TiO}_{2}$ solar cells with high photon-to-electron conversion efficiencies. Nature 395, 583-585 (1998).

14. Marsan, B. Cellules photovoltaïques électrochimiques à electrolyte polymère de configuration $n$-CdSe//POE modifié- $\mathrm{M}_{2} \mathrm{~S} / \mathrm{xS} / / \mathrm{ITO}$. PhD thesis, INRS-Énergie, Univ. Québec (1988).

15. Philias, J.-M. \& Marsan, B. All-solid-state photoelectrochemical cell based on a polymer electrolyte containing a new transparent and highly electropositive redox couple. Electrochim. Acta 44, 2915-2926 (1999).

16. Kay, A. et al. Artificial photosynthesis. 2. Investigations on the mechanism of photosensitization of nanocrystalline $\mathrm{TiO}_{2}$ solar cells by chlorophyll derivatives J. Phys. Chem. 98, 952-959 (1994).

17. Ardo, S. \& Meyer, G. Photodriven heterogeneous charge transfer with transitionmetal compounds anchored to $\mathrm{TiO}_{2}$ semiconductor surfaces. J. Chem. Soc. Rev. 38, 115-164 (2009).

18. Nusbaumer, H. et al. An alternative efficient redox couple for the dye-sensitized solar cell system. Chem. Eur. J. 9, 3756-3763 (2003).

19. Sapp, S. A. et al. Substituted polypyridine complexes of cobalt(II/III) as efficient electron-transfer mediators in dye-sensitized solar cells. J. Am. Chem. Soc. 124, 11215-11222 (2002).

20. Cazzanti, S. et al. Efficient non-corrosive electron-transfer mediator mixtures for dye-sensitized solar cells. J. Am. Chem. Soc. 128, 9996-9997 (2006).
21. Wang, P. et al. Charge separation and efficient light energy conversion in sensitized mesoscopic solar cells based on binary ionic liquids. J. Am. Chem. Soc 127, 6850-6856 (2005).

22. Wang, M. et al. The influence of charge transport and recombination on the performance of dye-sensitized solar cells. ChemPhysChem 10, 290-299 (2009).

23. O'Regan, B. et al. Measuring charge transport from transient photovoltage rise times. A new tool to investigate electron transport in nanoparticle films. J. Phys. Chem. B 110, 17155-17160 (2006).

24. Huang, S. et al. Charge recombination in dye-sensitized nanocrystalline $\mathrm{TiO}_{2}$ solar cells. J. Phys. Chem. B 101, 2576-2582 (1997).

25. Wang, M. et al. High-performance liquid and solid dye-sensitized solar cells based on a novel metal-free organic sensitizer. Adv. Mater. 20, 4460-4463 (2008).

\section{Acknowledgements}

The authors thank P. Comte for the $\mathrm{TiO}_{2}$ film fabrication, and C. Graetzel and K. Sivula for discussions. M.W., J.-E.M., R.H.-B., S.M.Z. and M.G. thank the Swiss National Science Foundation, and N.C., L.B. and B.M. thank the Natural Sciences and Engineering Research Council of Canada for financial support.

\section{Author contributions}

M.G., B.M. and S.M.Z. contributed to the conception and design of the experiments, analysis of the data and writing of the paper. N.C. and L.B. carried out the experiments and contributed to the materials. J.-E.M. and R.H.-B. analysed the data and contributed to the analysis tools. M.W. carried out the experiments, analysed the data and wrote the paper.

\section{Additional information}

The authors declare no competing financial interests. Supplementary information accompanies this paper at www.nature.com/naturechemistry. Reprints and permission information is available online at http://npg.nature.com/reprintsandpermissions/. Correspondence and requests for materials should be addressed to B.M., S.M.Z. and M.G. 